\begin{abstract}
"Mircea cel Batran" Naval Academy Scientific Bulletin, Volume XIX - 2016 - Issue 2
The journal is indexed in: PROQUEST / DOAJ / Crossref / EBSCOhost / INDEX COPERNICUS / DRJI / OAJI /

JOURNAL INDEX I I2OR / SCIENCE LIBRARY INDEX / Google Scholar / Academic Keys/ ROAD Open Access I

Academic Resources / Scientific Indexing Services / SCIPIO / JIFACTOR
\end{abstract}

\title{
ULTRACAPACITORS FOR TORPEDO PROPULSION
}

\author{
Deniz ÜNSALAN ${ }^{1}$ \\ Kunsel IZET-ÜNSALAN ${ }^{2}$
}

${ }^{1}$ Prof. Dr. Institute of Marine Sciences and Technology, Dokuz Eylül University, İzmir, Turkey
${ }^{2}$ Assoc. Prof. Dr.Ing. Faculty of Mechanical, Industial and Maritime Engineering, Ovidius University,
Constanta, Romania

Abstract- Ultracapacitors are electrochemical devices that are able to supply high time rates of energy and have the advantages of having virtually infinite charge-discharge cycles and are fast charging. Those properties have made them attractive for the storage of intermittent energy. Their main drawback so far has been considered their lower energy storage capacities. However, in the last few years, breakthroughs in efforts to improve their energy capacities have been achieved mainly by the use of carbon nanotube technology and carbon aerogel materials.

Propulsion systems of torpedoes launched from both surface and submarine ships have to provide high powers for higher speeds, have to have a sufficient supply of energy to achieve higher ranges, have to be reuseable and be serviceable onboard, as well as being silent and free from exhaust gas signature, if possible. Those requirements has lead the authors to consider ultracapacitors as sources for torpedo propulsion- able to supply higher powers, re-useable for exercises, rechargeable onboard the ship, silent and free from exhaust gas. Higher ranges are achievable by the allocation of the space saved from the air supply/fuel storage requirements and the replacement of heat engine by the more compact electric motor for ultracapacitor banks. It is deemed that the ultracapacitors of the near future shall also be feasible alternatives for Aluminum-Silveroxide torpedo batteries since they are rechargeable.

A parametric analysis involving the comparison of the proposed system by an existing hypothetical 21 inch $(533 \mathrm{~mm})$ torpedo propelled by a heat engine running on the Otto fuel.

Keywords: Ultracapacitor, Nanotechnology, Torpedo propulsion, Otto fuel, Aluminum-Silveroxide battery

\section{Introduction}

Torpedoes have been formidable naval weapons, as witnessed by their wide usage and high kill rates during the wars of the last 150 years, following the first self propelled torpedo of Whitehead in 1866 . They can be launched from surface ships, submarines or aircraft, using torpedo tubes or missiles, and against both surface and underwater targets. Recent developments in torpedoes are concentrated on increasing their range and speed by using advanced propulsion systems, that can use both chemical fuels via heat engines or by advanced batteries.

A torpedo propulsion system can be considered to be composed of three units: the energy source, the engine and the propulsor. Energy source can be a fuel and an oxidizer, a single-component fuel, or an electric battery or another source of stored energy. The engine can be a heat engine or an electric motor. A torpedo propulsor can be a classical propeller, a dual-rotation propeller or a pumpjet.

The demands from the torpedo propulsion system are high range, high speed and stealth - silent operation and no visible exhaust gases. Electric propulsion provides a silent operation with no exhaust gases, but however, until the recent

DOI: 10.21279/1454-864X-16-12-047

(c) 2015. This work is licensed under the Creative Commons Attribution-Noncommercial-Share Alike 4.0 License. developments in battery technology, electric propulsion has been regarded inferior to heat engine propulsion due to the lower energy and power concentrations. Another property should be re-useability, because a torpedo is used mainly as an exercise weapon at peace and non-combat periods and has a single-use in combat periods where it is used for the delivery of an explosive charge against the target. Also, the torpedo should be maintainable on board, due to logistic considerations. Electric propulsion has also the advantages of constant weight and constant power output: As the stored energy is depleted, the buoyancy characteristics of the torpedo do not change and the need for depth control is reduced. Heat engines used for torpedo propulsion have to operate against an exhaust backpressure, which reduces the engine outpult with increasing depths of operation. Electric propulsion eliminates that problem.

Modern torpedo batteries, which use either lithium or silver, are mainly of the primary type, which means they should be replaced after each usage, which is a process that requires dedicated shore or tender ship based facilities.

A modern development in the storage of energy is the recent and continuing development of ultracapacitors- which provide the advantages of 
"Mircea cel Batran" Naval Academy Scientific Bulletin, Volume XIX - 2016 - Issue 2 The journal is indexed in: PROQUEST / DOAJ / Crossref / EBSCOhost / INDEX COPERNICUS / DRJI / OAJI I JOURNAL INDEX / I2OR / SCIENCE LIBRARY INDEX / Google Scholar / Academic Keys/ ROAD Open Access I Academic Resources / Scientific Indexing Services / SCIPIO / JIFACTOR

high power capacities, short charging periods, virtually an infinite number of charge-discharge cycles, while being inferior to other energy storage modes from the point of energy capacity. However, recent developments have resulted in increasing the energy capacity of ultracapacitors, which has lead the authors to consider them as energy sources for torpedoes. This presentation is about this proposed usage, highlighting the possible advantages of its adaptation as an energy source for torpedoes.

Ultracapacitors- Principles of operation and characteristics

An ultracapacitor stores energy by physically separating positive and negative charges. The charges are stored on two sets of electrodes divided by an insulator. Energy is stored by the polarization of ions in the electrolyte filling the space within the electrodes. There are no chemical changes on the electrodes, therefore, ultracapacitors have a long cycle life but their energy density is limited by the surface area exposed by the reversely charged electrodes. So far, the reason that their energy storage capacity is limited has been due to that reason. However, their capacity to be rapidly charged and discharged has made them attractive for short time energy storage and supply, with high power outputs for short periods. One of such applications is the energy storage for regenerative breaking and acceleration for hybrid and electric cars. A study of the history, fundamentals and current technology of ultracapacitors has been given by $\mathrm{Yu}$ et al [1].

The amount of energy stored in an ultracapacitor can be written in a way similar to the conventional capacitors:

$$
E=\frac{1}{2} C V^{2}
$$

As can be seen, the energy storage capacity of an ultracapacitor depends both on the capacitance and the potential difference of the two collectors.
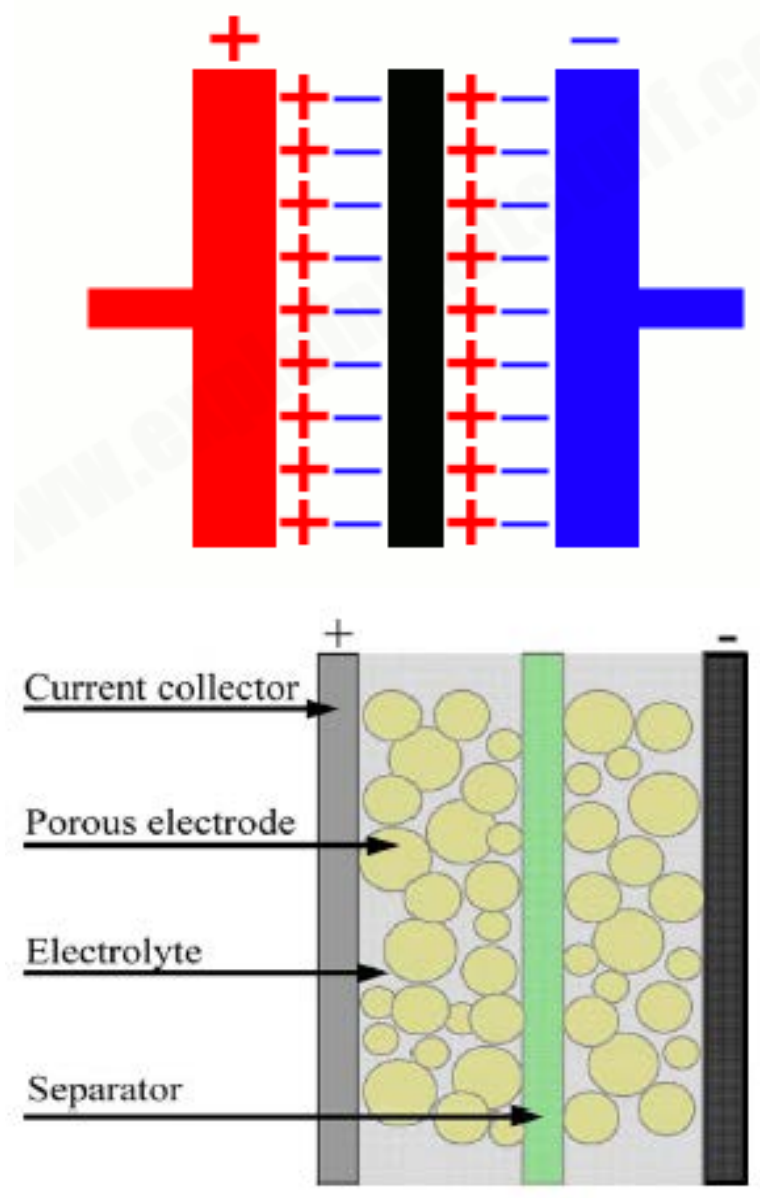

Figure 1. Principle of an ultracapacitor (From Khaligh and Lee, 2010)

Unfortunately, the electrolytes used in ultracapacitors limit the voltage to about 2.7 Volts, albeit it has been reported that the use of nonaqueous ("ionic") electrolytes make the use of about 4 Volts possible [1]. Therefore, the second way to increase the energy storage capacity lies in the increase of the capacitance, $C$. Since the capacitance of an ultracapacitor is proportional to the surface area, research has been made to increase the exposed surface area by using nanotechnology: Use of carbon-nanotubes and graphene sheets is one of the solutions, where specific capacitances of $150.9 \mathrm{~F} / \mathrm{g}$ corresponding to energy densities of about 85 W.h/kg (306 $\mathrm{kW} / \mathrm{kg}$ ) while delivering $4 \mathrm{~kW} / \mathrm{kg}$ power (at room temperature) has been achieved. [2], [3]. It is worth to note that the capacity increases with temperature: $136 \mathrm{~W} . \mathrm{h} / \mathrm{kg}(490 \mathrm{~kW} / \mathrm{kg})$ at $80{ }^{\circ} \mathrm{C}$ [3]. Another approach has been the use of aerogels, where specific capacitances up to $366 \mathrm{~F} / \mathrm{g}$ that do not deteriorate with increasing number of chargedischarge cycles have been achieved [4]. It is of no doubt that the capacities of available ultracapacitors shall reach to that of the rival Lithium-ion and silver-metal based primary 
"Mircea cel Batran" Naval Academy Scientific Bulletin, Volume XIX - 2016 - Issue 2

The journal is indexed in: PROQUEST / DOAJ / Crossref / EBSCOhost / INDEX COPERNICUS / DRJI / OAJI /

JOURNAL INDEX / I2OR / SCIENCE LIBRARY INDEX / Google Scholar / Academic Keys/ ROAD Open Access I Academic Resources / Scientific Indexing Services / SCIPIO I JIFACTOR

batteries in the near future, reaching the present 200-300 W.h/kg levels, while offering the obvious advantages of stealth, re-useability, and quick onboard and even in-tube charging.

Speed and range considerations for torpedoes Torpedoes should be both fast enough to engage their submarine or surface targets in the shortest time possible, and also should have a range sufficient enough for the distant targets. Those two requirements do conflict, and it becomes necessary to seek an optimization. To optimize the torpedo speed $\left(V_{t}\right)$ for a given torpedo with the given propulsive energy content $(E)$, and realizing that the torpedo can be treated as a ship obeying the standard procedures used in naval architecture, the time endurance $\left(t_{e}\right)$ for a torpedo is given as:

$$
t_{e}=\frac{E}{P_{D}}
$$

where $P_{D}$ is the delivered power to the propulsor. In terms of torpedo speed $\left(V_{t}\right)$, wetted surface area of the torpedo $(S)$, density of seawater $(\rho)$, coefficient of resistance $\left(C_{t}\right)$ and propulsive efficiency $\left(\eta_{\mathrm{P}}\right)$, time endurace becomes [5]:

$$
t_{e}=\frac{E}{\frac{\rho V_{t}^{3} S C_{t}}{2 \eta_{P}}}
$$

Assuming all the terms in the denominator with the exception of torpedo speed be a constant, $k_{1}$;

$$
t_{e}=\frac{E}{k_{1} V_{t}^{3}}
$$

On the other hand, time to engage a target ship ( $\left.\tau_{\text {eng }}\right)$, with speed $V_{s}$ escaping the torpedo (assuming perfect chase, there both the torpedo and target ship follow the same course),

$$
\tau_{\text {eng }}=\frac{R}{V_{t}-V_{s}}
$$

Equating the time to engage the target ship ( $\tau_{\text {eng }}$ ) and time endurance, the range of the torpedo at the rated speed $V_{t}$ is obtained:

$$
R=\frac{E}{k} \cdot \frac{V_{t}-V_{s}}{V_{t}^{3}}
$$

For the optimum torpedo speed with a maximum range, the last equation is derived with respect to the torpedo speed and set to zero:

$$
\frac{d R}{d V_{t}}=0
$$

from which the optimum torpedo speed is obtained for a given target ship:

$V_{t}=\frac{3}{2} V_{s}$

and the corresponding range:

$$
R=\frac{4}{27} \frac{E}{k V_{s}^{2}}
$$

Effective firing range, $L$, also in the "chase-mode", can be found by equating the distance travelled by the torpedo $\left(V_{t} \times t_{e}\right)$ and the distance travelled by the target at the same period $\left.\left(L+V_{s} \times t_{e}\right)\right)$ :

$$
V_{t} t_{e}=L+V_{s} t_{e}
$$

From which,

$$
L=\frac{1}{3} V_{t} t_{e}
$$

Since time endurance is $R / V_{t}$, it follows that $L=$ $R / 3$, or the maximum firing range in the chase mode is one-third of the torpedo range.

Taking the fact that a fast surface or a subsurface target seldom has a speed exceeding 35 knots (probably the upper limit for modern displacement type hull surface warships and submarines, the most feasible target for a high-speed torpedo), the torpedo speed of 52.5 knots $(27 \mathrm{~m} / \mathrm{s})$ is selected for the evaluation of the concept.

\section{Case study of a typical torpedo}

A hypothetical torpedo, with the external characteristics of U.S. Navy's Mk.48 torpedo is taken as the demonstration of performance of ultracapacitor power unit (Figure 2).

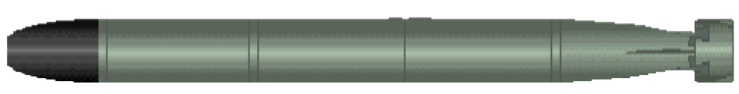

Figure 2. Mk.48 torpedo

(http://www.navysite.de/weapons/mk-48.htm)

The characteristic dimensions of the torpedo are given as:

Length

$5.79 \mathrm{~m}$ 


\section{"Mircea cel Batran" Naval Academy Scientific Bulletin, Volume XIX - 2016 - Issue 2 The journal is indexed in: PROQUEST / DOAJ / Crossref / EBSCOhost / INDEX COPERNICUS / DRJI / OAJI I JOURNAL INDEX I I2OR / SCIENCE LIBRARY INDEX / Google Scholar / Academic Keys/ ROAD Open Access I Academic Resources / Scientific Indexing Services / SCIPIO / JIFACTOR}

External diameter

$0.533 \mathrm{~m}$

Bow sonar dome diameter

$0.30 \mathrm{~m}$

Length of tail run

$1.20 \mathrm{~m}$

Parallel body length

$3.80 \mathrm{~m}$

Weight $1663 \mathrm{~kg}$

Warhead

$292.5 \mathrm{~kg}$

Coefficient of resistance of the torpedo was calculated from the correlations by Brooks and Lang [6] at 52.5 knots to be $C_{T}=0.0030$, corresponding to a propulsive power of $370 \mathrm{~kW}$, assuming a propulsive efficiency $\eta_{\mathrm{P}}=0.65$ by a pumpjet system, driven by an electric motor. For a range of 40000 meters at that speed, fired to an escaping target from a distance of about 13000 meters, the torpedo shall consume about $550 \mathrm{MJ}$ of energy, which shall be supplied by the ultracapacitors. If approximately 3 meters of parallel body is allocated for the ultracapacitors, the energy storage capacity of the ultracapacitors should be about $1 \mathrm{MJ} / \mathrm{liter}$, and for a neutral buoyancy contribution, about $1 \mathrm{MJ} / \mathrm{kg}$. However, the latest reported capacity is $306 \mathrm{~kJ} / \mathrm{kg}$ [2], about one-third of the targetted capacity. Nevertheless, it does not mean that ultacapacitor technology is not feasible for torpedoes. On the contrary, taking the developments in nanotechnology into account, there is no doubt that within a few years ultracapacitors shall be feasible alternatives for torpedo propulsion and also for both flying and undersea autonomous unmanned vehicles, due to its acoustic and bubble stealth advantages, being re-chargeable and re-useableness and elimination of battery life considerations.

\section{CONCLUSIONS}

Present day state of the art for ultra capacitors is still below the existing primary batteries and heat engine fuels, as can be seen from the table below. Expected efficiency (from the fuel to the propeller) of heatengine based systems (using petrol, ethyl alcohol, hydrogen peroxide and Otto fuel) was taken to be 0.25 , due to the maximum power conditions that they have to operate.

Table 1. Comparison of torpedo energy sources

\begin{tabular}{|c|c|c|c|c|c|c|}
\hline Energy source & $\begin{array}{c}\text { Lower } \\
\text { heating value } \\
(\mathrm{kJ} / \mathrm{kg})\end{array}$ & $\begin{array}{c}\text { Stochiometric } \\
\text { Air/Fuel ratio }\end{array}$ & $\begin{array}{c}\text { LHV, fuel/air } \\
\text { mixture } \\
(\mathrm{kJ} / \mathrm{kg})\end{array}$ & $\begin{array}{c}\text { Expected } \\
\text { efficiency }\end{array}$ & $\begin{array}{c}\text { Delivered } \\
\text { energy } \\
(\mathbf{k J} / \mathbf{k g})\end{array}$ & $\begin{array}{c}\text { Visible } \\
\text { track }\end{array}$ \\
\hline Petrol & 43500 & 14.7 & 2771 & 0.25 & $\mathbf{6 9 3}$ & Yes \\
\hline Ethyl alcohol & 28865 & 9 & 2887 & 0.25 & $\mathbf{7 2 2}$ & Yes \\
\hline $\begin{array}{c}\text { Hydrogen } \\
\text { peroxide }\end{array}$ & 2888 & 0 & - & 0.25 & $\mathbf{7 2 2}$ & Yes \\
\hline Otto Fuel & 2556 & 0 & - & 0.25 & $\mathbf{6 3 9}$ & Yes \\
\hline Li-Ion Battery & 460 & - & - & 0.90 & $\mathbf{4 1 4}$ & No \\
\hline AgO-Al Battery & 468 & - & - & 0.90 & $\mathbf{4 2 1}$ & No \\
\hline $\begin{array}{c}\text { Ultracapacitor } \\
\text { (Best achieved) }\end{array}$ & 306 & - & - & 0.90 & $\mathbf{2 7 5}$ & No \\
\hline
\end{tabular}

Despite the present inferiority of ultra capacitors as torpedo energy sources, the advantages achievable by their usage as the propulsive power sources are:

- Silent operation, with no trailing gas bubbles

- Weight and buoyancy characteristics do not change during the period of operation

- Engine performance is not affected with operation depth

- Are rechargeable and re-useable

- $\quad$ They can be charged onboard and in the torpedo tube.

- Battery life is long, with infinite charge /discharge cycles.

It should be stated that the results from the continuing research are encouraging and there is no doubt that the torpedoes of the near future shall take the advantage of ultra capacitors as energy sources, as well as all other applications so far using lithium-ion batteries. The main obstacle, limited energy storage capability can 
"Mircea cel Batran" Naval Academy Scientific Bulletin, Volume XIX - 2016 - Issue 2

The journal is indexed in: PROQUEST / DOAJ / Crossref / EBSCOhost / INDEX COPERNICUS / DRJI / OAJI I JOURNAL INDEX I I2OR / SCIENCE LIBRARY INDEX / Google Scholar / Academic Keys/ ROAD Open Access I Academic Resources / Scientific Indexing Services / SCIPIO / JIFACTOR

be overcome with the development of nano-technological materials to increase the capacitor effective surface area and with electrolytes that can endure higher voltages without chemical decomposition.

\section{BIBLIOGRAPHY}

[1] Yu, A., Chabot, V. Zhang, J., "Electrochemical Supercapacitors for Energy Storage and Delivery, Fundamentals and Applications", CRC Press, 2013

[2] Kannappan S., Kaliyappan K., Manian R.K., Pandian A.S., Yang H., Lee Y.S.,, Jang J.H., Lu W., "Graphene based Supercapacitors with Improved Specific Capacitance and Fast Charging Time at High Current Density", arXiv preprint arXiv:1311.1548, 2013.

[3] Liu,C., Yu,Z., Neff, D., Zhamu, A., and Jang B.Z., "Graphene-Based Supercapacitor with an Ultrahigh Energy Density", American Chemical Society Nano Lett. 2010, 10, 4863-4868

[4] Ye, S., Feng, J., Wu, P., "Deposition of Three-Dimensional Graphene Aerogel on Nickel Foam as a Binder-Free Supercapacitor Electrode", ACS Applied Materials \& Interfaces, 2013, 5, 7122-7129

[5] Larsson, L., Raven, H.C., Pauling, J.R., "Ship Resistance and Flow", Society of Naval Architercts and Marine Engineers, 2010

[6] Brooks, T.D., Lang, T.G., "Hydrodynamic Drag of Torpedoes", U.S. Naval Ordnance Test Station, NAVORD Report 5842, 18 February 1958 